\title{
DETERMINATION OF TRACE ELEMENT PROFILES IN \\ COARSE-GRAINED MINERALS BY EXTERNAL MILLIBEAM PIXE - A SCHORL TOURMALINE STUDY
}

\author{
A. LINDROOS, J-O. LILL, K-E. SAARELA, \\ L. HARJU and S-J. HESELIUS
}

LINDROOS, A.; LILL, J-O.; SAARELA, K-E.; HARJU, L. and HESELIUS SJ. 1995. Determination of trace element profiles in coarse-grained minerals by external millibeam PIXE - A schorl tourmaline study. Bull. Geol. Soc. Finland 67, Part 1, 47-59.

The thick-target PIXE technique was applied to direct analysis of trace elements in tourmaline minerals. Analyses of these minerals with conventional wet-chemical methods are difficult and time consuming. The PIXE analyses were carried out in air with a collimated proton beam. As the technique was used in combination with a polarizing microscope it provided excellent control over the spots analyzed. A scanning device was developed for remote-controlled spot analyses across the surface of the samples. Several scans were run across polished sections of multicrystal schorl-tourmaline aggregates. Pellets of crushed and ground tourmaline samples were also analyzed. The method was calibrated against USGS standard reference materials. The precision of the method varied between 1 and $10 \%$ and the detection limits were 1-10 ppm for most of the elements analyzed. Different sets of X-ray absorbers were used to improve the sensitivity and reliability of the method for the elements of interest. The concentrations of fourteen elements were calculated from their X-ray yields and the fluorine content was simultaneously determined using the $109.8 \mathrm{keV}$ gamma line.

The tourmaline samples were taken from a complex granite pegmatite on the Kimito island in SW Finland. They were found to contain mainly elements with $\mathrm{Z}<33$ (lighter than As). Relatively high concentrations of $\mathrm{Fe}, \mathrm{Zn}, \mathrm{Ga}$ and $\mathrm{F}$ were observed. Zinc was found to be a geochemically important minor element in schorl with a concentration ranging from 0.10 to $0.28 \%$. The pellets were found to contain inclusions of other minerals.

Key words: granites, pegmatite, tourmaline, schorl, trace elements, zinc, particle induced X-ray emission, Proterozoic, Kemiö, Finland.

A. Lindroos: Department of Geology and Mineralogy, Åbo Akademi University, FIN-20500 Turku, Finland.

J-O. Lill and S-J. Heselius: Accelerator Laboratory, Åbo Akademi University, FIN-20500 Turku, Finland.

K-E. Saarela and L. Harju: Department of Analytical Chemistry, Åbo Akademi University, FIN-20500 Turku, Finland. 


\section{INTRODUCTION}

Geological materials commonly consist of elements with atomic numbers ( $\mathrm{Z}$ values) ranging from 11 to 20 (Na-Ca), with the exception of iron $(\mathrm{Z}=26)$ and oxygen $(\mathrm{Z}=8)$. These elements can be analyzed with a variety conventional methods. X-ray fluorescence (XRF) is often used for the determination of the bulk composition of a solid sample and the electron microprobe (EMP) for point analyses and scans. Several high-quality methods for whole-rock, trace element analysis are also available. Point analysis of trace elements in the ppm range is more problematic and requires more sophisticated methods like laser ablation ICP-MS (Inductively Coupled Plasma-Mass Spectrometry), SIMS (Secondary Ion Mass Spectrometry) or other ionbeam analyses.

The chemical compositions of tourmalines are complex and difficult to determine. Wet-chemical methods require dissolution of the samples, e.g., by fusion with $\mathrm{LiBO}_{2}, \mathrm{H}_{3} \mathrm{BO}_{3}$ or $\mathrm{Na}_{2} \mathrm{O}_{2}$ as fluxes. High ratios of flux to sample, necessary for dissolution, result in a great risk for contamination from the reagents and a diminunation of element signal. Use of high temperatures implies loss of volatile elements. Crushing and grinding hard minerals like tourmaline can also cause contamination. For many analytical methods high iron content can cause interfering effects.

The Particle Induced X-ray Emission (PIXE) technique, first described by Johansson et al. (1970), provides an instrumental, usually nondestructive, method for the analyses of geological specimens. PIXE is a truly multi-elemental method, because elements with Z $>13$ can be analyzed simultaneously. The method utilizes a particle beam of an accelerator, usually a proton beam in the energy range $2-3 \mathrm{MeV}$, to induce characteristic X-rays from the elements of the sample to be analyzed. The PIXE method and variations of it are comprehensively described in e.g. Johansson and Campbell (1988).

In this study the MGC-20 cyclotron of the Åbo Akademi Accelerator Laboratory was used for thicktarget PIXE-analyses (TTPIXE) with an external proton beam. An great advantage with this technique is the handling of large samples during analyses along centimeter-scale profiles. The technique was applied to the analysis of trace elements in coarsegrained tourmaline minerals from a complex granite pegmatite from Mattkärr in SW Finland. These tourmalines have been earlier analyzed for the major elements by Lokka (1943) and the pegmatite has been described by Pehrman (1945) and Hazebroek and Lof (1976). Tourmalines are among the last minerals to crystallize in pegmatitic veins and their composition reflect the composition of the latestage residual liquids. Because they are very resistant to weathering they are locally important in soil geochemistry.

\section{EXPERIMENTAL}

\section{Irradiation conditions}

The Åbo Akademi $103 \mathrm{~cm}$ cyclotron was used to produce a beam of $3 \mathrm{MeV}$ protons incident on the target sample situated outside the cyclotron-vacuum system (Fig. 1). A $7.5 \mu \mathrm{m}$ Kapton foil was used as particle beam-exit window separating the cyclotron vacuum from the laboratory atmosphere. The beam was collimated to a diameter of $1 \mathrm{~mm}$. The integrated charge on the target was measured indirectly utilizing measurement of light emission induced in air by the particle beam (Lill et al., 1993b). The light is mainly due to molecular band transitions of $\mathrm{N}_{2}$. The integrated charge is needed in the normalization of the measured X-ray yields for the quantification of the results.

The samples were mounted with a planar surface facing the particle beam and the X-ray detector at angles of $45^{\circ}$ (Fig. 1). A scanning device was developed for the remote control of the sample. The samples could be moved in vertical and horizontal directions without changing the irradiation/ measuring geometry. The irradiations were monitored with a video camera. 


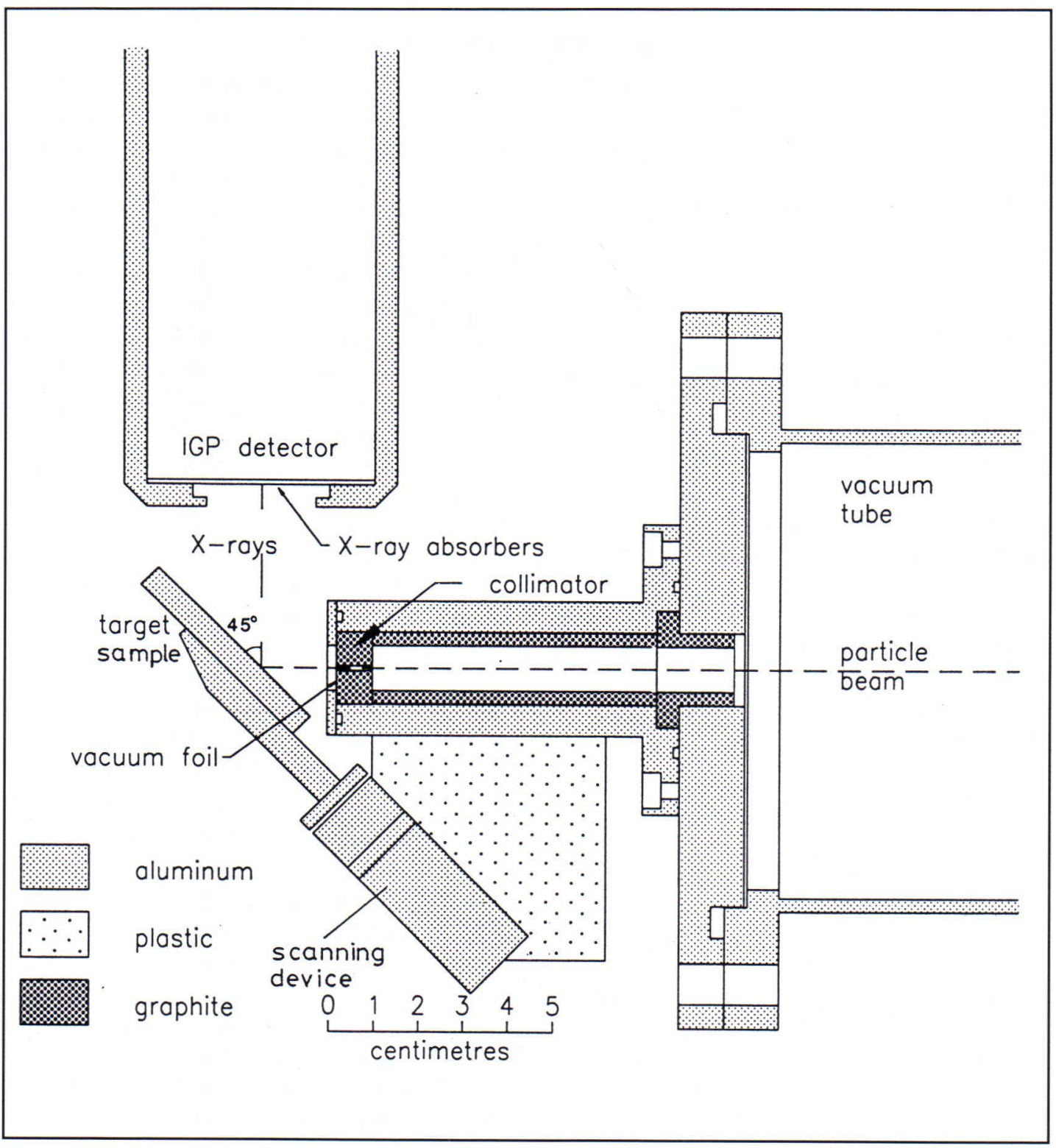

Fig. 1. Cut-away drawing of external beam irradiation facility for TTPIXE analysis.

\section{Data collection}

An intrinsic germanium planar (IGP) detector with a $25 \mu \mathrm{m}$ thick beryllium window was used in the experimental setup (Fig. 1). The resolution (FWHM) of the IGP detector was
$165 \mathrm{eV}$ at $5.9 \mathrm{keV}$. A Canberra 2020 spectroscopic amplifier was used for pulse shaping. The A/D conversion was done with a Canberra 8075 ADC connected to a Nuclear Data 66 multichannel analyzer. The recorded Xray spectra were transferred to a PC and 
analyzed off-line with a commercial peakanalyzing program (SAMPO 90). FORTRAN programs were used for the identification of the peaks in the X-ray energy spectra and for the normalization of the obtained peak areas.

The IGP detector (thickness $5 \mathrm{~mm}$ ) is preferable to an ordinary $\mathrm{Si}(\mathrm{Li})$-detector, as the efficiency of the IGP detector remains on an acceptable level even at energies up to $100 \mathrm{keV}$. In addition to high-energy $\mathrm{X}$-rays, a gamma line due to the ${ }^{19} \mathrm{~F}\left(\mathrm{p}, \mathrm{p}^{\prime} \gamma\right){ }^{19} \mathrm{~F}$ reaction was obtained and recorded. This was of special interest as fluorine is difficult to analyze in geological samples with conventional methods.

\section{Sample preparation}

The TTPIXE method enables direct analyses of solid samples. In this work $0.1 \mathrm{~mm}$ polished uncovered thin sections of minerals for polarizing microscopy were studied. Only mineral sections larger than $1 \mathrm{~mm}^{2}$ could be analyzed without risk for contribution from neighbouring minerals due to the coarse spatial resolution of the proton beam. The irradiated spots on a $0.1 \mathrm{~mm}$ thick tourmaline section can be seen in Fig. 2. The colour changes are due to radiation damage in the minerals. The irradiated area was about $1 \mathrm{~mm}^{2}$ per spot and had an elliptical shape due to the $45^{\circ}$ angle between the sample surface and the particle beam (Fig. 1).

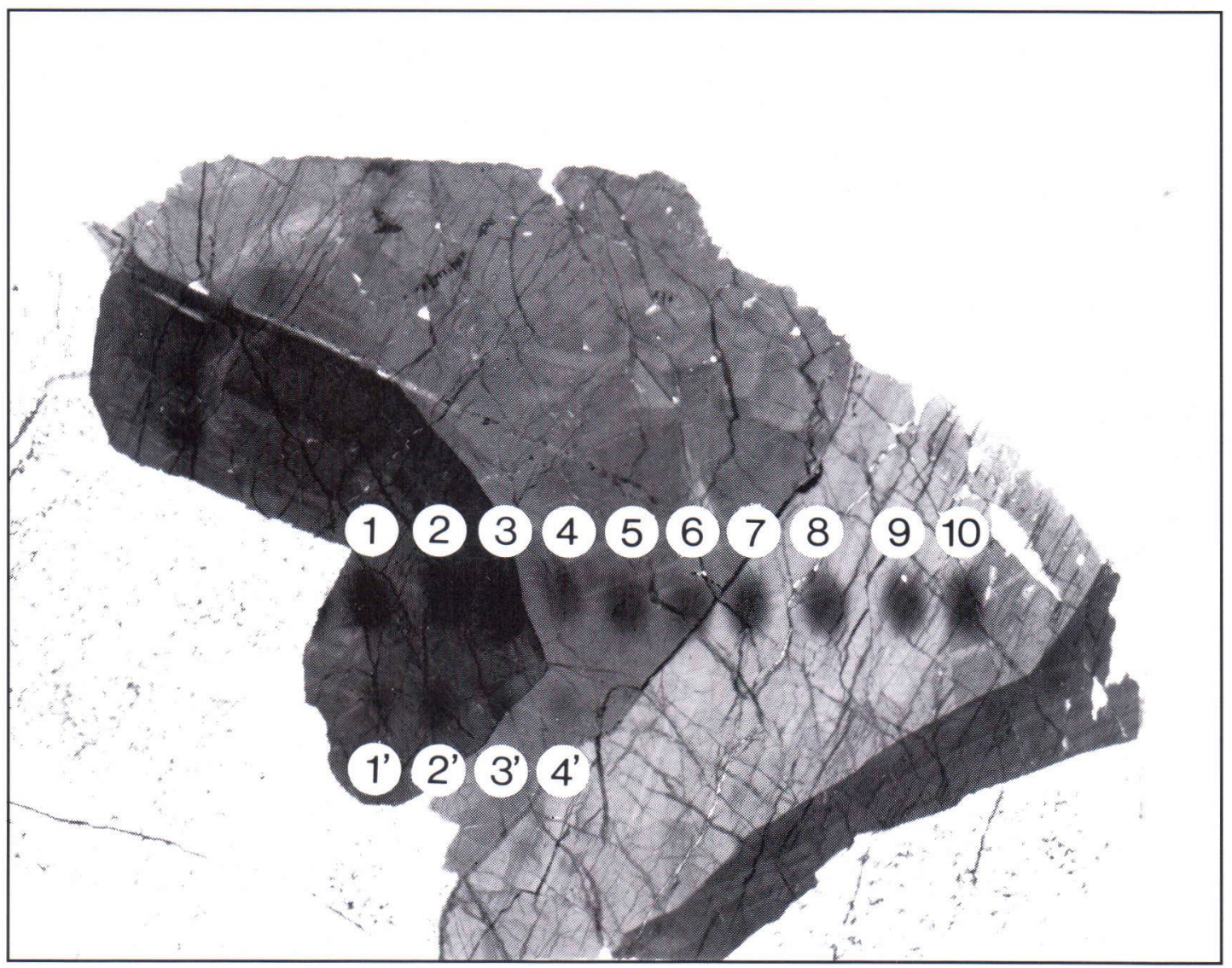

Fig. 2. Pantographic picture of the $0.1 \mathrm{~mm}$ thick tourmaline section. The irradiated areas can be seen as dark spots. The distances between the centres of the spots are $2 \mathrm{~mm}$. The numbers refer to the analyses in Tables 1 and 2 (spots 1-3 are in the dark brown-green schorl, spots 4-6 are in the brown-green schorl with bluish staining and spots 7-10 are in the transparent blue schorl). 
The diffuse edges of the irradiated areas (Fig. 2) are due to scattering of the protons in the beamexit foil and in the air between the foil and the sample.

The silicon carbide grinding powder and the glue used for sample mounting were also analyzed and the risk of contamination found to be minimal. Pellets representing a composite tourmaline sample were prepared for comparative purposes from ground tourmaline and spectroscopically pure graphite powder. For further details of pellet preparation see Lill et al. (1993a).

\section{Calibration procedure}

Powder pellets of United States Geological Survey Standard Reference Material (USGS SRM) BCR-1 (basalt) were prepared for the quantification of the results. The SRM pellets were analyzed in six different spots and the arithmethic mean values used for calibration. The precision of the method was calculated as the relative standard deviation (RSD) of these measurements. The RSDs thus include the heterogenity of the SRM. A ratio between the mean value for the peak area, normalized with respect to the integrated charge, and certified concentration was determined empirically for each element and each set of Xray absorbers.

Germanium was readily detectable in some tourmaline samples but the concentrations in the USGS SRMs were below the detection limits. The Ge concentrations in tourmaline were therefore calculated using the measured X-ray yield to concentration ratio for gallium in the SRM. This approximation can be made considering the following: The $\mathrm{K}_{\alpha} \mathrm{X}$-ray yield for an element is mainly due to the particle induced $\mathrm{K}$-shell ionization cross section, the detector efficiency and, of course, the elemental concentration. The detector efficiency depends strongly on the X-ray energy. The $\mathrm{K}_{\alpha}$-energies for $\mathrm{Ga}$ and $\mathrm{Ge}$ are close to each other $(9.24 \mathrm{keV}$ for $\mathrm{Ga}$ and $9.87 \mathrm{keV}$ for $\mathrm{Ge})$. The cross section for proton-induced, K-shell ionization in $\mathrm{Ga}$ is $128 \times 10^{-24} \mathrm{~cm}^{2}$ and in Ge $98 \times$ $10^{-24} \mathrm{~cm}^{2}$ (Cohen and Harrigan, 1985).
$X$-ray filters

In this work two different sets of absorbers were used to attenuate the X-rays between the sample and the detector. A $3 \mathrm{~mm}$ polycarbonate filter with a $0.5 \mathrm{~mm}$ hole (funny filter) was used to smooth the X-ray spectra and thereby improve the multielement character of the method. This absorber was used in the determination of the major elements. The heavier trace elements were detected using a 10 ìm chromium foil on a 0.1 $\mathrm{mm}$ thick polyester backing (critical absorber) combined with two $0.35 \mathrm{~mm}$ thick Mylar foils. These filters strongly attenuated the K X-rays from iron and the lighter major elements and thereby increased the sensitivity for the detection of $\mathrm{K} \mathrm{X}$ rays from heavier trace elements. Secondary Xrays from the chromium foil precluded the analysis of chromium and vanadium. Manganese analyses were also affected by secondary X-rays but the Mn concentrations were still well above the detection limits.

\section{Analytical limitations}

A limitation of the PIXE-technique is that the lightest elements up to aluminum cannot generally be detected. In our setup, however, fluorine could be detected utilizing the gamma line at $109.8 \mathrm{keV}$. Also cesium, barium and the REE are usually difficult to analyze with the same accuracy as the other heavy trace elements in geological samples. The K X-ray yields are low for these elements and the $\mathrm{L} \mathrm{X-rays} \mathrm{appear} \mathrm{in} \mathrm{the} \mathrm{same} \mathrm{energy} \mathrm{region} \mathrm{as}$ the $\mathrm{K} \mathrm{X}$-rays from some of the major elements. In the tourmaline analyses the detection limits were about $100 \mathrm{ppm}$.

Additionally, the determination of low potassium concentrations with the external beam setup used in this work was difficult. The detection limit for potassium was high due to a spectral peak overlap with K X-rays from argon in the beam path. The interference was minimized by the funny filter which for these energies served as a collimator for the emitted X-rays. 


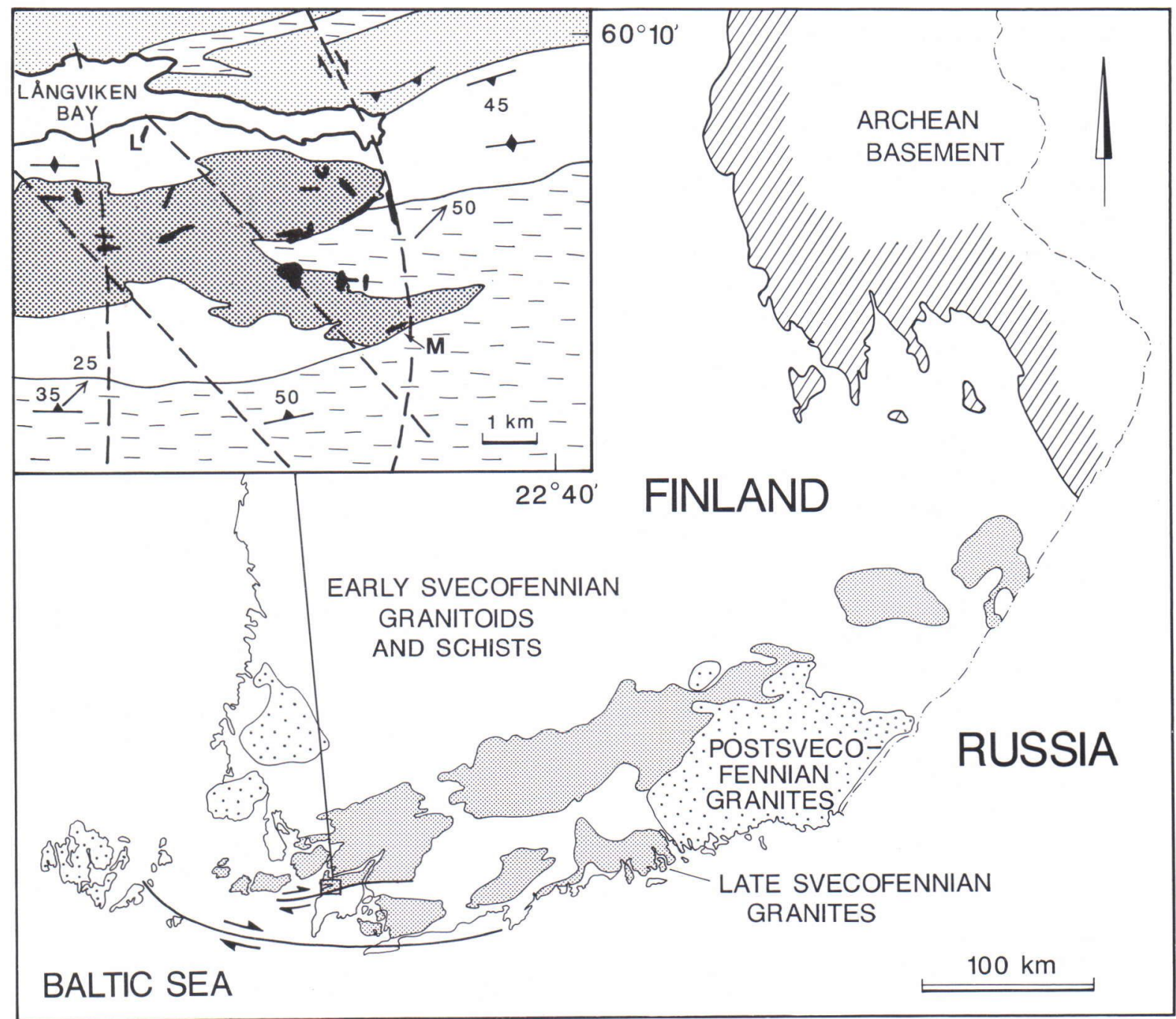

Late Svecofennian rocks

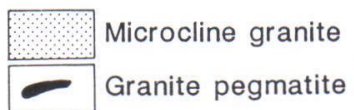

Early Svecofennian rocks

\begin{tabular}{l}
\hline Granitoids \\
Gabbro \\
- - Schists
\end{tabular}

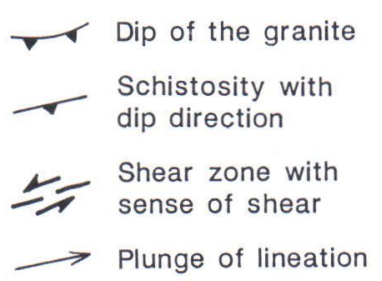

Fig. 3. Simplified geological sketch map of southern Finland (modified from Ehlers and Lindroos, 1992) with inserted geological map of the Mattkärr area compiled from observations by Pehrman (1945), Seitsaari (1956) and by the authors. $M=$ Mattkärr pegmatite, $L=$ Lövböle pegmatite. 


\section{GEOLOGICAL BACKGROUND AND SAMPLING}

The tourmaline samples were taken from a complex granite pegmatite in Mattkärr on the Kimito (or Kemiö) island in SW Finland (Fig. 3). The Kimito pegmatites are well known among mineralogists since the 18th century for their rare minerals (e.g. Pehrman, 1945). The Sm-Nd isochron age of allanite, apatite, gadolinite and garnet of one of the pegmatites

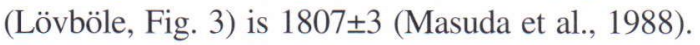
The pegmatites are spatially related to a large 1.83 Ga (Suominen, 1991) microcline granite intruded into $1.88 \mathrm{Ga}$ (Huhma, 1986) early Svecofennian schists and granitoids. The pegmatites occur mainly on the southern side of the microcline granite, in a brecciated gabbro belonging to the early Svecofennian suite. The brecciation of the gabbro and the emplacement of the granite took place during a long period of east-western dextral shearing in a transpressional tectonic regime (Ehlers et al., 1993).

The Mattkärr pegmatite is situated about $4 \mathrm{~km}$ south of the microcline granite in the southern margin of the brecciated gabbro. Only the dump of a small quarry covered by a road is left. The original width of the pegmatite was a few meters and the length some tens of meters. The strike is east-west and the dip is steep. The main minerals are K-feldspar (microcline), quartz, muscovite and tourmaline. Large albite crystals are sparse and beryl, sphene, cassiterite, tantalite and columbite occur as accessories together with an unidentified metamict brown iron-manganese phosphate. Microscopic pyrite and chalcopyrite grains occur along fractures in the main minerals. Metallic gold and bismuth grains have also been identified with scanning electron microscope (SEM). Spinel, triplite and topaz have been reported by Pehrman (1945) and apatite by Hazebroek and Lof (1976).

Tourmaline has grown during late stages of the shear movements and the crystals have responded to the stress field by forming new crystallographic orientations or by fracturing. In Mattkärr they can be partly replaced by hydrothermal quartz and in more sheared pegmatites they are altered to micas. The colour is black in hand specimen and greyish green in thin sections with pleochroism towards greyish blue-green. In the $0.1 \mathrm{~mm}$ thin sections the

Table 1. TTPIXE analyses of the BRC-1 and schorl tourmaline specimens. Columns $I^{\prime}-4$ ' refer to spots in a profile parallel to the profile shown in Fig 2. Kul and Ku2 denote tourmalines from Kuortane and Pe a tourmaline from Peräseinäjoki. All concentrations are per cent.

\begin{tabular}{|c|c|c|c|c|c|c|c|c|c|c|c|c|}
\hline \multirow[t]{3}{*}{ Element } & \multicolumn{2}{|c|}{ BCR-1 $(n=6)$} & \multicolumn{7}{|c|}{ Mattkärr tourmalines } & \multirow{3}{*}{ Ku1 } & \multirow{3}{*}{$\mathrm{Ku} 2$} & \multirow{3}{*}{$\mathrm{Pe}$} \\
\hline & \multirow{2}{*}{$\begin{array}{l}\text { Cert. } \\
\text { value }\end{array}$} & \multirow{2}{*}{$\begin{array}{l}\text { RSD } \\
(\%)\end{array}$} & \multicolumn{4}{|c|}{ Tourmaline spots } & \multicolumn{2}{|c|}{ Pellet $(n=6)$} & \multirow{2}{*}{$\begin{array}{l}\text { Lokka } \\
\text { (1943) }\end{array}$} & & & \\
\hline & & & 1 ' & 2 & 3 ' & $4^{\prime}$ & Mean & $\operatorname{RSD}(\%)$ & & & & \\
\hline $\mathrm{SiO}_{2}$ & 54.50 & 5.5 & 33 & 28 & 45 & 31 & 32 & 17 & 34.61 & n.d. & n.d. & n.d. \\
\hline $\mathrm{K}_{2} \mathrm{O}$ & 1.70 & 6.5 & bdl & bdl & bdl & 0.08 & 0.30 & $(n<6)$ & 0.28 & bdl & 0.20 & 0.35 \\
\hline $\mathrm{CaO}$ & 6.92 & 2.6 & 0.04 & 0.51 & 0.05 & 0.58 & 1.39 & 17 & 0.57 & 0.05 & 0.17 & 0.22 \\
\hline $\mathrm{TiO}_{2}$ & 2.20 & 3.3 & 0.38 & 0.29 & 0.31 & 0.23 & 0.27 & 5.3 & 0.41 & 0.37 & 0.53 & 0.30 \\
\hline $\mathrm{MnO}$ & 0.18 & 1.0 & 0.20 & 0.26 & 0.27 & 0.22 & 0.19 & 9.1 & 0.23 & 0.45 & 0.31 & 0.73 \\
\hline $\mathrm{FeO} *$ & 12.76 & 0.7 & 17,9 & 17.9 & 18.0 & 18.1 & 15.2 & 1.5 & 16.27 & 17.8 & 15.2 & 16.4 \\
\hline $\mathrm{ZnO}$ & 0.015 & 5.7 & 0.224 & 0.223 & 0.230 & 0.248 & 0.120 & 1.2 & n.d. & 0.349 & 0.158 & 0.183 \\
\hline $\mathrm{F}$ & 0.047 & 9.4 & 0.72 & 0.77 & 0.67 & 0.86 & 0.67 & 5.7 & 0.95 & 0.46 & 0.34 & 0.48 \\
\hline
\end{tabular}

bdl $=$ below the detection limit

$(n<6)=$ elemental concentration could not be measured in every irradiated spot. n.d. $=$ not determined. 


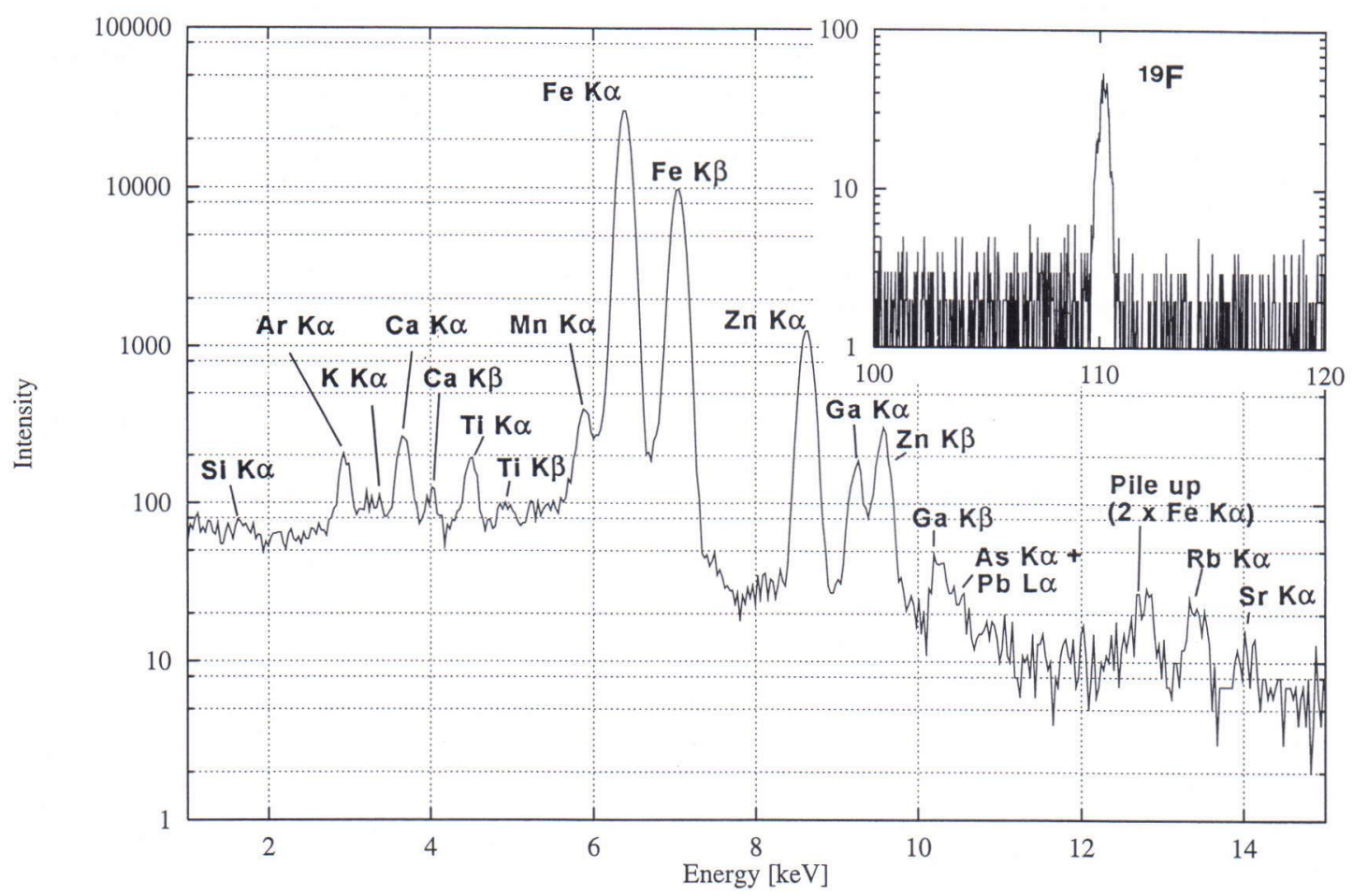

Fig. 4. X-ray spectrum for the determination of the major elements of spot 3' in Fig. 2. The ${ }^{19} \mathrm{~F}$-gamma line is shown in the insert.

tourmalines are dark brown-green, brown-green with bluish staining or clear blue. Several crystallographic orientations are also usually present in the same specimen as seen in Fig. 2. The tourmalines can also be zoned with a light core and a dark rim with the same crystallographic orientation.

\section{RESULTS}

\section{Major element composition of tourmalines}

Major elements were analyzed in a short 4-spot row across the dark tourmaline specimen in Fig. 2 and in six spots in the tourmaline pellet. The results are presented in Table 1 together with published values (Lokka, 1943; wet-chemical methods) of a tourmaline from Mattkärr. The results are not directly comparable, because separate specimens were studied. The results of the pellet analysis are yet quite close to the values given by Lokka. The certified values of the SRM and the relative standard deviation (RSD) of six determinations are also included in the table. The funny filter was used to smooth out the X-ray spectra. The concentrations of silicon are near the detection limit (due to the filtering) and the RSD is large. A typical X-ray spectrum for the analysis of tourmaline is shown in Fig. 4.

Because rather high zinc concentrations were detected with TTPIXE in the Mattkärr schorl tourmalines, schorls from two other localities were also analyzed (Table 1). Two specimens are from a complex pegmatite in Kuortane $200 \mathrm{~km}$ 
Table 2. Trace-element analyses of spots 1-10 (fig. 2) and tourmaline pellet. The RDSs of the analyses of the SRM BCR-1 are included. The concentrations are given in ppm expect for iron (in \%).

\begin{tabular}{|c|c|c|c|c|c|c|c|c|c|c|c|c|c|c|}
\hline \multirow[t]{2}{*}{ Element } & \multicolumn{5}{|c|}{ Tourmaline spots } & \multirow[b]{2}{*}{6} & \multirow[b]{2}{*}{7} & \multirow[b]{2}{*}{8} & \multirow[b]{2}{*}{9} & \multicolumn{3}{|c|}{ Pellet } & \multicolumn{2}{|c|}{ BCR-1 $(n=6)$} \\
\hline & 1 & 2 & 3 & 4 & 5 & & & & & 10 & $\begin{array}{l}\text { Mean } \\
(n=6)\end{array}$ & $\begin{array}{l}\text { RSD } \\
(\%)\end{array}$ & $\begin{array}{l}\text { Certif. } \\
\text { value }\end{array}$ & $\begin{array}{l}\text { RSD } \\
(\%)\end{array}$ \\
\hline $\mathrm{F}$ & 7030 & 7710 & 7520 & 8060 & 7810 & 6620 & 7660 & 7200 & 7290 & 6710 & 6680 & 5.7 & 470 & 6.3 \\
\hline $\mathrm{Ti}$ & 1920 & 1700 & 1820 & 1340 & 1290 & 1270 & 1100 & 660 & 680 & 540 & 1620 & 5.3 & 13200 & 4.9 \\
\hline Mn & 1570 & 1660 & 1600 & 1690 & 1670 & 1640 & 1660 & 1480 & 1470 & 1360 & 1450 & 9.1 & 1400 & 8.6 \\
\hline $\mathrm{Fe}$ & 12.4 & 12.2 & 12.6 & 12.8 & 13.0 & 12.9 & 13.0 & 12.0 & 11.9 & 11.5 & 10.8 & 1.5 & 9.38 & 0.76 \\
\hline $\mathrm{Zn}$ & 1480 & 1420 & 1500 & 1600 & 1600 & 1610 & 1600 & 1270 & 1240 & 1190 & 959 & 1.2 & 120 & 4.0 \\
\hline $\mathrm{Ga}$ & 134 & 140 & 140 & 133 & 134 & 136 & 127 & 113 & 121 & 107 & 240 & 19 & 20 & 12 \\
\hline $\mathrm{Ge}$ & 15 & 16 & 17 & 15 & 13 & 17 & 13 & bdl & 11 & bdl & 44 & 15 & bdl & \\
\hline $\mathrm{Rb}$ & 20 & 24 & 15 & 15 & 13 & 18 & 22 & 18 & 16 & 21 & 38 & 10 & 46.6 & 0.72 \\
\hline $\mathrm{Sr}$ & 7 & 27 & bdl & 11 & bdl & bdl & 12 & bdl & bdl & 19 & 18 & 39 & 330 & 0.68 \\
\hline $\mathrm{Nb}$ & 11 & bdl & bdl & bdl & bdl & bdl & 20 & bdl & bdl & bdl & 600 & 37 & 13.5 & 19 \\
\hline Sn & 11 & 25 & bdl & bdl & bdl & bdl & bdl & bdl & bdl & 21 & 390 & 41 & bdl & \\
\hline $\mathrm{Pb}$ & 22 & 25 & 21 & 21 & 16 & bdl & bdl & bdl & bdl & bdl & 22 & 19 & 17.6 & 7.5 \\
\hline $\begin{array}{l}\text { Accessory } \\
\text { elements }\end{array}$ & As & & & & & As & As, $Y$ & As & & $\mathrm{Au}$ & $\mathrm{Ta}, \mathrm{W}$ & & & \\
\hline
\end{tabular}

bdl $=$ below the detection limit.

north of Mattkärr and one is from Peräseinäjoki $250 \mathrm{~km}$ north of Mattkärr. Also these specimens showed high zinc concentrations.

\section{Trace elemental profiles}

The analysis of trace elements with $\mathrm{Z}>26$ (heavier than iron) was the main scope of this study. The relative $\mathrm{X}$-ray yields from these elements were increased by attenuating the $\mathrm{K}$ X-rays from iron by the set of absorbers comprising a chromium foil and two Mylar foils (section 2.5). The results are presented in Table 2.

Profiles for some of the elements analyzed are plotted in Fig. 5. Most of the profiles show a clear fractionation between the different crystals and different coloured zones within the crystals, although point 7 is chemically more similar to points 4-6 than points 8-10 in the same crystal. The variation in the fluorine content is rather irregular with concentration drops near fractures and grain boundaries. The transition elements Fe, $\mathrm{Mn}$ and $\mathrm{Zn}$ have very similar patterns, while Ti shows a pattern more similar to $\mathrm{Ga}$ and $\mathrm{Ge}$.

\section{DISCUSSION}

\section{The TTPIXE method}

The TTPIXE method combined with the sample scanning device and a video monitoring system provided accurate control of what was actually analyzed in the mineral sections. The irradiated area of the sample was about $1 \mathrm{~mm}^{2}$ per spot and had an elliptical shape due to the $45^{\circ}$ angle between the sample surface and the particle beam. The stopping range of a $3 \mathrm{MeV}$ proton beam in tourmaline is 82 $\mu \mathrm{m}$ (Ziegler and Biersack, 1985). The normal penetration depth was $58 \mu \mathrm{m}$. Hence the irradiated volume was $0.1 \mathrm{~mm}^{3}$ or $0.3 \mathrm{mg}$ (the density of tourmaline taken as $3.227 \mathrm{~g} / \mathrm{cm}^{3}$; Lokka, 1943). The measured elemental concentration does not represent the average concentration for an element in the irradiated volume. The proton beam energy decreases with the penetration depth in the material. This affects the ionization cross section which decreases as well as the X-ray production. Furthermore, the degree of absorption of the X-rays increases with depth of origin and also depends on 

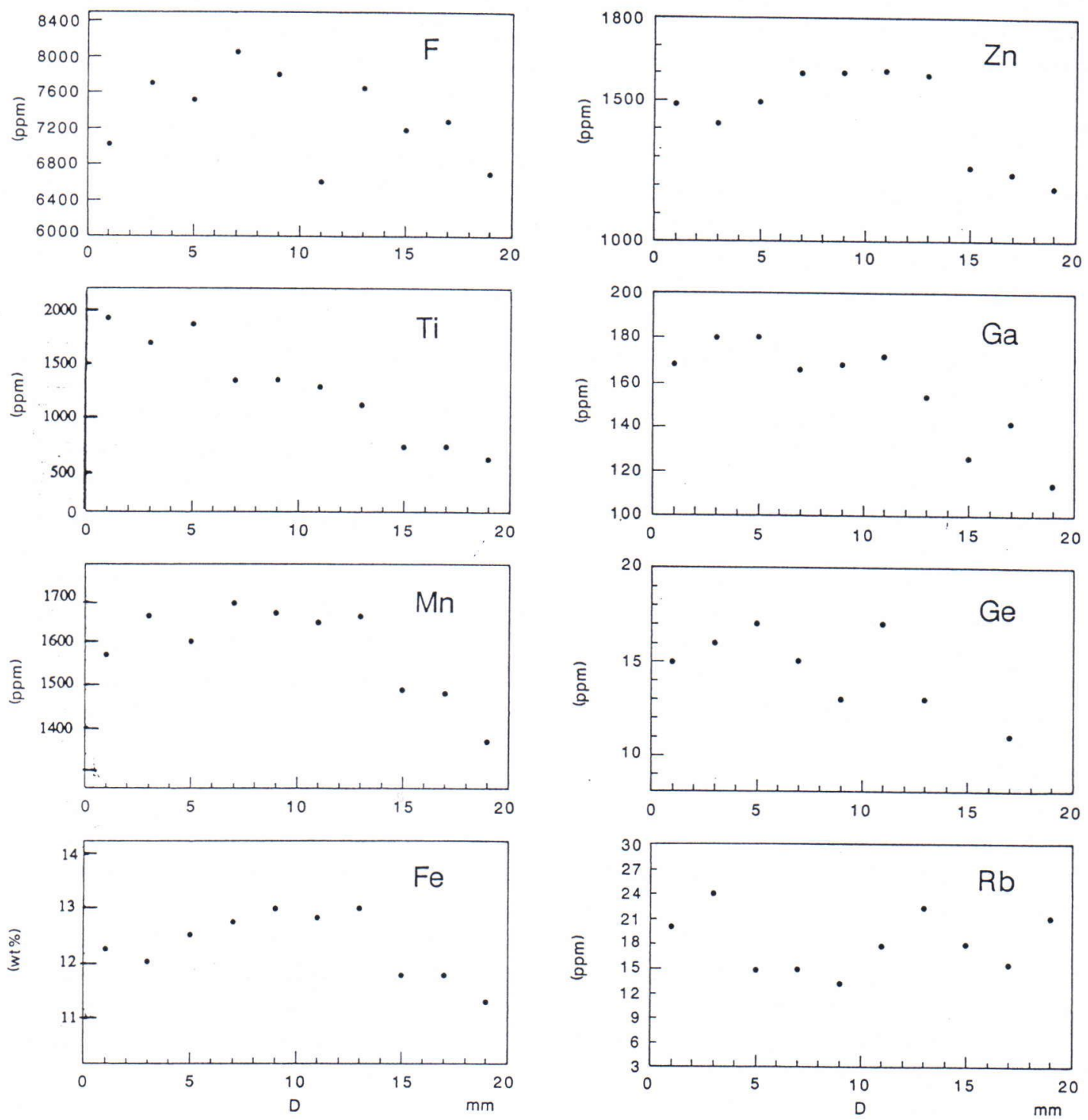

Fig. 5. Elemental concentration profiles for row of spots seen in Fig. 2.

the sample composition and density. Thus, elements in the surface layers of the irradiated volume are more likely to produce detectable X-rays than elements located at the end of the beam path.

The elemental concentrations reported in this work represent a small part of the irradiated volume. The main part of the detected X-rays originates from a region down to a depth of a few tens of $\mu \mathrm{m}$. This feature gives possibilities to visually determine whether the concentrations represent a pure mineral or whether inclusions or contaminated fractures are present in the mineral. This information is lost in analyses where a grinding or dissolving procedure is involved. 
Compared with EMP analyses of minor and trace elements the PIXE analyses are of higher sensitivity. Zinc, which is usually not detected in tourmaline samples with EMP, is one of the most suitable elements to be analyzed with PIXE.

\section{The tourmalines}

The tourmalines studied are schorl end-members with a high iron and a low alkali content. The fluorine, zinc and gallium values are high. According to Deer et al. (1986) the chemical formula for schorl tourmaline can be written $\mathrm{Na}(\mathrm{Fe}, \mathrm{Mn})_{3} \mathrm{Al}_{6} \mathrm{~B}_{3} \mathrm{Si}_{6}(\mathrm{O}, \mathrm{OH})_{30}(\mathrm{OH}, \mathrm{F})$. Usually iron is mainly ferrous. The concentrations of the other major elements in the Mattkärr schorl are according to Lokka (1943): $10.03 \% \mathrm{~B}_{2} \mathrm{O}_{3}, 33.65 \%$ $\mathrm{Al}_{2} \mathrm{O}_{3} .0 .20 \% \mathrm{MgO}, 1.67 \% \mathrm{Na}_{2} \mathrm{O}, 1.21 \% \mathrm{H}_{2} \mathrm{O}+$ and $0.11 \% \mathrm{H}_{2} \mathrm{O}$-. Iron is reported as $6.18 \% \mathrm{Fe}_{2} \mathrm{O}_{3}$ and $10.09 \% \mathrm{FeO}$. The high proportion of ferric iron is exceptional. The aluminum content is, however, normal. The ferric iron thus substitutes ferrous iron and not aluminum. $\mathrm{Zn}$ and $\mathrm{Ti}$ are as abundant as Mn in the Mattkärr schorl. They are also considered to substitute for ferrous iron (Deer et al., 1986).

Zinc is not usually reported as a minor element in schorl tourmaline (e.g. Manning, 1982; Deer et al., 1986; Foit, 1989). This is because tourmalines are usually analyzed with EMP and the zinc concentations are just below the detection limit of the technique (e.g. Grice and Ercit, 1993). High zinc concentrations have, however, also been reported. (Jolliff et al., 1986). This study suggests that zinc is as common as manganese in many schorls. Zinc is probably the element which most easily substitutes ferrous iron since the ionic radius of both $\mathrm{Zn}^{2+}$ and $\mathrm{Fe}^{2+}$ is $74 \mathrm{pm}(0.74 \AA)$ according to Berger (1991). The concentration of zinc in schorl therefore reflects the concentration of zinc in the residual granite melts. Zinc concentrations in a highly refractory mineral like tourmaline should also be considered when interpreting zinc distribution in soil samples. Although iron and zinc are highly compatible in schorl, copper on the other hand is highly incompatible at least in the presence of a minor sulphide phase.

The dark crystals are clearly enriched in titanium compared with the greenish crystals and especially the transparent blue ones. The correlation between Ti content and a dark brown colour in schorls has earlier been described by Black (1971) and Mannig (1982). They found no other correlations between any of the main elements determined with EMP and pleochroic colour. Our results also suggest a correlation between dark colour and titanium content. However, there remains the possibility that the dark colour results from both ferric iron and titanium substituting for ferrous iron. The ionic radius of $\mathrm{Ti}^{4+}=68 \mathrm{pm}(0.68 \AA)$ is close to that of $\mathrm{Fe}^{3+}=64 \mathrm{pm}(0.64 \AA)$ according to Berger (1991). The darkening caused by the proton irradiation shows that not only the composition determines the colour of tourmaline.

The concentrations of $\mathrm{K}, \mathrm{Rb}, \mathrm{Nb}, \mathrm{Sn}$, and $\mathrm{Ta}$ are low in the tourmaline profile, but higher in the pellet. The higher concentrations obtained for the pellet and by the wet chemical analysis (potassium values by Lokka, 1943) are due to microscopic micas in fractures in the tourmaline. $\mathrm{Ta}, \mathrm{Nb}$, and Sn also occur as columbite-tantalite-cassiterite inclusions. Arsenic and gold are present in microfractures and voids in the tourmalines as well as in the other main minerals. Tungsten and partly tantalum are contaminants from the tungsten carbide mill used in the pellet preparation. Calcium and strontium are unevenly distributed and enriched in the pellet. The concentrations of these elements are probably affected by secondary calcite, which is common in fractures and slickenside surfaces in the area.

\section{CONCLUSIONS}

From the analytical point of view the PIXE technique has many advantages for the study of refractory minerals in comparison with e.g. wetchemical methods. The method is relatively nondestructive for geological samples and allows the determination of many elements simultaneously. 
The sample preparation is simple; solid samples of minerals and rocks can be directly analyzed and it is easy to control what is actually being analyzed with the scanning and monitoring systems developed. Contamination from grinding materials and from reagents used for dissolution of the sample can thus be avoided. A great advantage is also that germanium and tin and the anionic elements e.g. fluorine, chlorine, bromine, iodine, sulphur and phosphorus can be analyzed.

The millibeam PIXE technique provides a powerful instrument for a geologist in combination with a polarizing microscope. The mineral grains to be analyzed can be selected with the polarizing microscope and then they can be accurately analyzed with the PIXE method for almost all trace elements present in concentrations above approximately $10 \mathrm{ppm}$. After the analysis the sample can be re-examined with the microscope. When several multielement minerals or if several phases of one mineral exist, the geochemical history of the sample can be reconstructed.

The simplest way to obtain quantitative determinations with PIXE is to choose a standard reference material with a major-element composition as similar as possible to the samples studied. The analytical error due to matrix effects is small in PIXE compared with many other analytical techniques (e.g. Johansson and Campbell, 1988; Maenhaut, 1990). Tests carried out on different standard reference materials showed, that the reliability and the accuracy of the method are good. For most elements the relative errors of the determination is clearly below $10 \%$. The sensitivity of the method is good. For the trace elements studied a detection limit in the region 1 - 10 ppm can be achieved, mainly depending on the set of absorbers used.

About twenty elements were detected in the Mattkärr tourmalines, and the concentration of fourteen elements could be determined quantitatively. The agreement of our results with earlier published wet-chemical data for tourmaline samples from the same site in Mattkärr (Lokka, 1943 ) is good. The tourmalines could be classified as a schorl end-member rich in F, Zn and Ga. The high zinc concentrations were not expected. This is mainly because very few analyses of zinc in schorl have been reported in the literature.

This work has demonstrated that external millibeam PIXE is a useful method in mineral analysis. PIXE enables direct reliable analysis of trace elements in single mineral grains without risk for contamination.

ACKNOWLEDGEMENTS: The authors gratefully acknowledge the financial support provided by the University Council of Åbo Akademi. The authors also wish to express their gratitude to Klas Malmqvist and the PIXE group at the University of Lund and Lund Institute of Technology for cooperation. Mrs Merja Puumala drew the figures and Mr Veikko Grönroos prepared the thin section.

\section{REFERENCES}

Berger, L.I., 1991. Symmetry of crystals. In: D.R. Lide (Editor-in-Chief), Handbook of Chemistry and Physics, 72nd Edition 1991-92. CRC Press, Inc., Boca Raton, Ann Arbor and Boston, p. 12-8.

Black, P.M., 1971. Tourmalines from Cuvier island, New Zealand. Mineralogical Magazine 38, 374-376.

Cohen, D.D. and Harrigan, M., 1985. K- and L-shell ionization cross section for protons and helium ions calculated in the ECPSSR theory. Atomic Data and Nuclear Data Tables 33, 255-343.
Deer, W.A., Howie, R.A. and Zussman, J., 1986. RockForming Minerals, 1B. Disilicates and Ring Silicates. John Wiley \& Sons, Inc., New York, $629 \mathrm{pp}$.

Ehlers, C. and Lindroos, A., 1992. Evolution of early Proterozoic crust in southern Finland-Emplacement of anatectic granites along mid-crustal subhorisontal shears. Abstract, 29th International Geological Congress, Aug. 24 - Sept. 3, 1992. Kyoto, Japan. Vol. 2, p. 536. 
Ehlers, C., Lindroos, A. and Selonen, O., 1993. The late Svecofennian granite-migmatite zone of southern Finland - a belt of transpressive deformation and granite emplacement. Precambrian Research 64, 295-309.

Foit, F.F., Jr., 1989. Crystal chemistry of alkali-deficient schorl and tourmaline structural relationships. American Mineralogist 74, 422-431.

Grice, J.D. and Ercit, T.S., 1993. Ordering of $\mathrm{Fe}$ and $\mathrm{Mg}$ in tourmaline crystal structure: The correct formula. Neues Jahrbuch fur Mineralogie. Abhandlungen 165, 3, 245-266.

Hazebroek, H.P. and Lof, P., 1976. Petrology and mineralogy of some selected pegmatites of the Kimito peninsula, SW Finland. Unpublished M.Sc. thesis, Free University of Amsterdam, $118 \mathrm{pp}$.

Huhma, H., 1986. Sm-Nd, U-Pb and $\mathrm{Pb}-\mathrm{Pb}$ isotopic evidence for the origin of the early Proterozoic Svecokarelian crust in Finland. Geological Survey of Finland, Bulletin 337, 48 pp.

Johansson, S.A.E. and Campbell, J.L., 1988. PIXE a Novel Technique for Elemental Analysis. Wiley, New York, $347 \mathrm{pp}$.

Johansson, T.B., Akselsson, R. and Johansson, S.A.E., 1970. X-ray analysis: Elemental trace analysis at the $10^{-12} \mathrm{~g}$ level. Nuclear Instruments and Methods in Physics Research 84, 141-143.

Jolliff, B.L., Papike, J.J. and Shearer, C.K., 1986. Tourmaline as a recorder of pegmatite evolution: Bob Ingersoll pegmatite, Black Hills, South Dakota. American Mineralogist 71, 472-500.

Lill, J-O., Hernberg, F., Heselius, S-J. and Wickström, $T ., 1993 a$. Experimental setup for non-vacuum PIXE. In: S-J. Heselius (Editor), The Åbo Akademi Accelerator Laboratory Triennial Report 1990-92 (Åbo
Akademi University, Portansg. 3, FIN-20500 Turku, Finland), 31-34.

Lill, J-O., Saarela, K-E., Hernberg, F.J., Heselius, S-J. and Harju, L., 1993b. A novel method for charge integration in external beam TTPIXE. Application to analyses of biological materials. Nucl. Instr. and Meth. B83, 387-393.

Lokka, L., 1943. Beiträge zur kenntnis des chemismus der Finnischen minerale. Bulletin de la Commission Géologique de Finland 129, p. 44.

Maenhaut, W., 1990. Recent advances in nuclear and atomic spectrometric techniques for trace element analysis. A new look at the position of PIXE. Nuclear Instrumets and Methods in Physics Research B49, 518-532.

Manning, D.A.C., 1982. Chemical and morphological variation in tourmalines from the Hub Kapong batholith of peninsular Thailand. Mineralogical Magazine 45, 139147.

Masuda, A., Shimizu, H., Nakai, S., Makishima, A. and Lahti, S., 1988. La â-decay constant estimated from geochronological studies. Earth and Planetary Science Letters 89, 316-322.

Pehrman, G., 1945. Die granitpegmatite von Kimito (S.W.Finnland) und ihre minerale. Acta Academiae Aboensis, Mathematica et Physica XV.2. 84 pp.

Seitsaari, J., 1955. Geological map of Finland 1:100 000, sheet 2012. Geological Survey of Finland.

Suominen, V., 1991. The chronostratigraphy of southwestern Finland with special reference to Postjotnian and Subjotnian diabases. Geol. Surv. Finl. Bull. 356, 100 pp.

Ziegler, J.F. and Biersack, J.P., 1985. The Stopping and Range of Ions in Solids, Pergamon Press, New York, $321 \mathrm{pp}$. 